\title{
ZU LIVIUS IV 56, 13 (TEXTKRITIK)
}

\begin{abstract}
The codex $V$ (eronensis) indicates that after the word magistratuumque one word is missing. The sense of the sentence and the space which is free in $V$ suggest that the word aditorum ought to be inserted.
\end{abstract}

R. M. Ogilvie setzt in seiner Ausgabe (Oxford 1974) zwischen magistratuumque und uerecundia (IV 56,13) das Zeichen für einen locus desperatus.

Während die codices Symmachiani zwischen den beiden Wörtern keinen Abstand freihalten, findet sich im Codex Veronensis rescriptus ${ }^{1}$ eine lacuna; dort ist nach dem Platz für zwei Buchstaben ein $i$ zu lesen, dann ist der Platz für 4 bis 5 Buchstaben frei, worauf erst uerecundia folgt. Mommsen hatte ui atque uerecundia ergänzt, was einerseits zu dem Platz (d.h. der Stellung des $i$ ) nicht ganz stimmt und anderseits sehr blaß wirkt.

Ogilvie erwägt, omnium uerecundia zu schreiben, was ebenfalls mit dem Platz nicht ganz zusammenstimmt und in der Bedeutung noch weniger paßt, da eben nicht alle Magistrate unmittelbar mit der in Rede stehenden Angelegenheit befaßt wurden. Auch unter dem politischen Aspekt empfiehlt sich diese Lesung nicht (vgl. laeti discordia patrum, IV $56,10)$. So möchte ich also den Vorschlag machen, nach magistratuumque bzw. vor uerecundia das Wort aditorum einzufügen. Dieses entspricht den räumlichen Verhältnissen vollkommen: ..i.....(.); das Wort aditorum (8 Buchstaben, wobei im Falle der Rechnung mit 7 Buchstaben die Endung in Abbreviatur gestanden haben könnte) füllt also auf den Buchstaben genau die Lücke und trifft sich genau mit dem erhaltenen $i$. Auch inhaltlich fügt sich unsere Konjektur zur Bemerkung: cum primores

1 Uber die Codices vgl. T. Livi ad urbe condita, ed. R. M. Ogilvie, Bd. 1, S. VI ff. mit Lit. 
patrum..., postremo etiam tribunos plebi appellarent et consulibus quoque ab ea potestate uim super tali re inhibitam referrent (IV 56, 10). Die magistratus aditi, die eben damit befaßt worden waren, auf die man (neben den Gesetzen) Rücksicht zu nehmen habe, sind ja an dieser Stelle genannt. Der so sanierte Satz lautet demgemäß: interim patricii soluti legum magistratuumque aditorum uerecundia per se tribuniciam quoque potestatem agerent. Der Beistrich nach uerecundia in der Oxford-Ausgabe ist irrefuihrend; legum magistratuumque aditorum uerecundia schränkt soluti ein. Das Wort solutus kann ja auch 'willkürlich' heißen, daher muß die Bedeutung durch uerecundia ins rechte Licht gerückt werden. Die Volkstribunen wollen sagen, daß in diesem Staat nicht alles im Lot sei, daß aber jetzt die primores patrum zu ihnen gleichsam bitten kämen; die patricii sollten gefälligst inzwischen agieren, freilich in Eigenverantwortlichkeit (soluti), doch mit Rücksicht auf die Gesetze und auf die magistratus aditi, die sich ihnen gegenüber so großzügig gezeigt hätten (...per se tribuniciam quoque potestatem agerent).

WALTER PöTsCher 